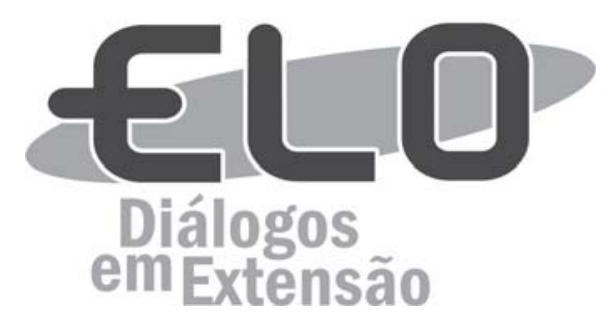

\title{
Oficinas para construção de brinquedos pedagógicos: Uma experiência com grupos sociais vulneráveis
}

Sylvana Karla da Silva de Lemos Santos ${ }^{1}$, Erika Barretto Fernandes Cruvinel ${ }^{2}$, Rafaela Maria de Medeiros Fernandes Rocha ${ }^{3}$, Magali Melo dos Santos ${ }^{4}$, Karla Danielle Lima Pereira ${ }^{5}$, Débora Augusta da Silva ${ }^{6}$

\begin{abstract}
Resumo: Trata-se de um relato de experiência que descreve as atividades desenvolvidas no Projeto de extensão "É brincando que se aprende", concebido por um grupo de mulheres com o objetivo de oferecer recursos teóricos e práticos para a atuação dos participantes junto a crianças de até seis anos de idade. Cada brinquedo confeccionado teve, obrigatoriamente, um propósito pedagógico para servir como estímulo sensorial às crianças, além do caráter lúdico. Os participantes da oficina foram motivados a utilizar embalagens de alimentos e materiais escolares, como papel, tesoura, lápis e cola. Para a construção e o emprego dos brinquedos, foram fornecidas orientações, de acordo com a faixa etária apropriada, e sugestões para construção de outros objetos indicados em sítios web. Além da qualificação profissional, a oficina contribuiu com o fortalecimento dos laços familiares, na medida em que o aprendizado pode e deve ser reproduzido no âmbito doméstico.
\end{abstract}

Palavras-chave: Brinquedos. Infância. Reuso de materiais. Aprendizagem.

Área Temática: Educação.

\section{Workshops for building educational toys: An experience with vulnerable social groups}

Abstract: This is an experience report that describes the activities developed in the "It is joking what is learned" extension project, conceived by a group of women with the objective of offering theoretical and practical resources for the participants works with children up to six years old. Each toy had, necessarily, a pedagogical purpose to serve as a sensorial stimulus to the children, besides the playful character. Workshop participants were encouraged to use food packaging and school supplies such as paper, scissors, pencils and glue. For the construction of toys, guidelines given for the use of toys, according to the appropriate age group, and suggestions for building other objects indicated on websites. In addition to professional qualification, the workshop contributed to the strengthening of family ties, in that the learning can and should be reproduced at home.

Keywords: Toys. Childhood. Reuse of materials. Learning.

\section{Talleres para construir juguetes educativos: una experiencia con grupos sociales vulnerables}

Resumen: Este es un informe de experiencia que describe las actividades desarrolladas en el proyecto de extensión "Es jugando lo que se aprende", concebido por un grupo de mujeres con el objetivo de ofrecer recursos teóricos y prácticos para que los participantes trabajen con niños de hasta seis años. Cada juguete tenía, necesariamente, un propósito pedagógico para servir como un estímulo sensorial para los niños, además

\footnotetext{
${ }^{1}$ Doutoranda em Ciência da Informação na Universidade de Brasília. Docente no Instituto Federal de Brasília, Campus Brasília, DF. Via L2 Norte, SGAN 610, Módulo D, E, F e G. CEP: 70830-450. Brasília, DF.

2 Doutora em Ecologia pela Universidade de Brasília. Docente no Instituto Federal de Brasília, Campus Gama, DF.

${ }^{3}$ Mestre em Psicologia, educadora perinatal e consultadora em amamentação. Voluntária no grupo de casais grávidos Ishtar Brasília, DF.

${ }^{4}$ Administradora, doula, arteterapeuta, educadora perinatal e consultadora em amamentação. Voluntária no grupo de casais grávidos Ishtar Brasília, DF.

${ }^{5}$ Graduanda do curso Tecnólogo em Logística no Instituto Federal de Brasília, Campus Gama, DF.

${ }^{6}$ Licenciada em Dança, egressa do Instituto Federal de Brasília, Campus Brasília, DF.
} 
del personaje lúdico. Se alentó a los participantes del taller a utilizar envases de alimentos y materiales escolares como papel, tijeras, lápices y pegamento. Para la construcción de juguetes, se dieron pautas para el uso de juguetes, según el grupo de edad apropiado, y sugerencias para construir otros objetos indicados en los sitios web. Además de la calificación profesional, el taller contribuyó al fortalecimiento de los lazos familiares, ya que el aprendizaje puede y debe reproducirse en el hogar.

Palabras clave: Juguetes. Infancia. Reutilización de materiales. Aprendizaje.

\section{Introdução}

A infância é uma fase da vida cheia de descobertas e de experimentos proporcionada pelo brincar e pelo jogar, ferramentas essenciais para a criança (SOUSA; SANTOS; GAMA, 2016). É por meio de jogos e de brincadeiras que as crianças podem ampliar os "conhecimentos sobre si, sobre os outros e sobre o mundo que está ao seu redor" e, assim, desenvolver capacidades importantes para toda a vida (SANTOS, 2011). "As crianças possuem uma natureza singular, que as caracteriza como seres que sentem e pensam o mundo de um jeito muito próprio" (BRASIL, 1998).

Moyles (2002) considera que o brincar favorece a estimulação do cérebro para a sua ativação, o que motiva e desafia o brincante a buscar respostas ao que desconhece. Ao participar da construção do brinquedo, o indivíduo tende a perceber as características do objeto criado e a assimilar sua função, além de demonstrar interesse. Nesse contexto, a construção de brinquedos com o uso de materiais de descarte e de baixo custo é um atrativo que pode ser empregado tanto no âmbito educacional, quanto no laboral.

A importância do brinquedo decorre de sua capacidade de instigar a imaginação infantil. Ao ver o brinquedo, a criança é tocada pela sua proposta, reconhece umas coisas, descobre outras, experimenta e reinventa, analisa, compara e cria. Sua imaginação se desenvolve e suas habilidades também (SANTOS, et al., 2016, p. 290-291).

Pensando no atendimento por meio da formação extensionista, a oficina É brincando que se aprende foi concebida com o intuito de promover a criação de brinquedos a partir de materiais de descarte, com fins pedagógicos e lúdicos, e também de qualificação profissional (tanto para a produção e comercialização de brinquedos acabados, quanto para a prestação de serviços de entretenimento em festas infantis). Em sua primeira edição, em 2016, a oficina teve como objetivo oferecer aos seus participantes recursos teóricos e práticos para atuarem junto a crianças de seis meses a seis anos de idade, o que corresponde à primeira infância (BRASIL, 2016). Os participantes foram estudantes de cursos técnicos e de licenciatura do Instituto Federal de Brasília (IFB), além de mães e pais da comunidade externa, totalizando 15 indivíduos. O projeto contou com recursos financeiros do Edital de fomento a projetos de extensão Qualific Express, que custeou a aquisição de materiais para a oficina (papel, tesoura, lápis, cola, barbante, entre outros).

No ano seguinte, em 2017, o projeto "É brincando que se aprende" obteve novo financiamento de modo a prosseguir com a oferta e incorporou o atendimento a dois grupos socialmente vulneráveis, egressos do sistema prisional do Distrito Federal (DF) e suas famílias e moradores do Núcleo Rural Alagado da Suzana (Gama-DF). Na época, as instituições que representam tais grupos, Associação de Apoio aos Presos, Egressos e Familiares (APEF) e Fundação Seara Espiritual a Caminho da Luz, apresentaram demanda de qualificação e requalificação à coordenação do projeto. A partir daí, novas estratégias de oferta de oficinas foram traçadas para atender ao público específico.

\section{Objetivo}

Relatar a experiência do projeto "É brincando que se aprende" que buscou: (1) contribuir para a promoção do protagonismo social e cidadania de crianças, jovens e adultos de grupos socialmente vulneráveis; (2) possibilitar o desenvolvimento da criatividade e promover momentos de ludicidade para crianças, jovens e adultos de grupos socialmente vulneráveis; (3) promover a conscientização ambiental para questões relacionadas ao descarte inadequado de resíduos sólidos; (4) despertar em crianças, jovens e adultos de grupos socialmente vulneráveis o interesse pela construção de brinquedos pedagógicos a partir de materiais de descarte; e (5) qualificar trabalhadores para o ingresso e/ou reingresso no mundo do trabalho. 


\section{Metodologia \\ O público atendido}

O projeto "É brincando que se aprende" atendeu crianças, jovens e adultos de dois grupos socialmente vulneráveis: egressos do sistema prisional do DF e suas famílias, a partir da parceria firmada com a APEF; e moradores do Núcleo Rural Alagado da Suzana (Gama-DF), a partir da parceria firmada com a Fundação Seara Espiritual a Caminho da Luz. As parcerias foram firmadas por meio de Carta de Anuência e Apoio à Oficina pela Instituição Parceira para posterior assinatura de Acordo de Cooperação Técnica firmado com o Instituto Federal de Brasília (IFB) conforme previsto no Edital No 048/RIFB, de 3 de novembro de 2016. As duas instituições parceiras foram responsáveis pela divulgação do projeto junto aos grupos atendidos, realização de inscrições e organização do espaço para a execução das oficinas.

A APEF é uma associação sem fins lucrativos que, através de parcerias com entidades públicas e privadas, busca desenvolver projetos de assistência social e também de profissionalização com foco na ressocialização dos egressos do sistema prisional. Criada em 1979, como Grupo Cristão de Evangelização Penitenciária (GCEP), busca atender aos anseios dos encarcerados, aos seus familiares e à comunidade que convive com essa realidade e sempre trabalhou na busca por um sistema prisional mais humano, pela ressocialização dos apenados, pelo auxílio às famílias dos que se encontram no cárcere e pela justiça restaurativa.

O Núcleo Rural Alagado da Suzana está localizado no Gama Leste, a $5 \mathrm{~km}$ do Campus Gama do IFB, sendo uma comunidade que não dispõe de escola, posto de saúde, calçamento e saneamento, onde moram 32 famílias, as quais, em sua maioria, vivem exclusivamente com recursos dos programas sociais de governo. O Núcleo foi constituído pelo Governo do DF na década de 70 e as famílias foram assentadas na área com o objetivo de abrigar projetos de caráter religiosos e sociais. Ao longo do tempo, o Núcleo foi se descaracterizando e, atualmente, apenas a Fundação Seara Espiritual a Caminho da Luz desenvolve projetos sociais na comunidade. A Seara Espiritual a Caminho da Luz é uma fundação sem fins lucrativos, criada em 2002, com o objetivo de desenvolver projetos que buscam disseminar a cultura da paz e do amor sem ter vinculação com qualquer igreja.

\section{A equipe executora}

A equipe executora foi composta por: duas servidoras (das áreas de Ciências Ambientais e Ciências da Informação) e quatro alunas do IFB, sendo três voluntárias dos cursos Proeja em Administração e Superior de Tecnologia em Logística, além de uma bolsista da Licenciatura em Dança e da parceria com o grupo Ishtar Brasília ${ }^{7}$ mediante a participação de uma psicóloga e educadora perinatal, e de uma arterapeuta e doula. A formação multidisciplinar da equipe executora promoveu diferentes abordagens acerca dos temas trabalhados nas oficinas.

\section{As oficinas}

As oficinas realizadas tiveram uma carga horária de três horas. Antes de iniciar cada oficina, a equipe mediadora fazia uma breve provocação para que os participantes se apresentassem, compartilhassem seus nomes e experiências com a elaboração de brinquedos. Em seguida, a equipe fornecia explicações quanto à dinâmica da oficina.

As oficinas foram divididas em três momentos. No primeiro momento, de acordo com o público e a faixa etária, foram abordados temas teóricos (desenvolvimento infantil e a importância dos brinquedos e das brincadeiras; empreendedorismo e mercado de trabalho; meio ambiente). A teoria do desenvolvimento infantil foi tratada com base nos princípios da psicologia, segundo Bee (2003).

No segundo momento, era realizada a construção dos brinquedos. A proposta para a construção de brinquedos e brincadeiras era executada com base no Referencial Curricular Nacional para a Educação Infantil (BRASIL, 1998), ao fazer uso de materiais escolares, como papel, tesoura, lápis e cola. Durante a construção dos brinquedos selecionados para a oficina, também eram fornecidas indicação de sítios web, blogs e páginas em redes sociais, onde os participantes poderiam encontrar orientações para a elaboração de outros brinquedos.

No terceiro momento, os participantes eram convidados a socializar voluntariamente com o grupo uma breve avaliação sobre a condução da equipe e a sua participação na oficina, dificuldades encontradas, sensações e sentimentos aflorados e perspectivas de utilização dos conhecimentos construídos. 
Todos os brinquedos trabalhados nas oficinas foram selecionados com propósitos pedagógicos, especialmente para a estimulação sensorial e motora de crianças. Além de utilizar materiais de descarte e outros de baixo custo, a oficina estimulou a construção coletiva dos brinquedos pelas famílias e pela comunidade, incluindo a participação das crianças.

$\mathrm{Na}$ fase de planejamento das oficinas, a equipe executora elaborou modelos de cada um dos brinquedos a serem construídos e montou um portfólio que era apresentado aos participantes, para que eles pudessem conhecer os brinquedos e sua importância pedagógica antes de iniciarem a construção.

\section{Brinquedos Pedagógicos}

A proposta de construção dos brinquedos pedagógicos incluiu dez peças, conforme descritas no Quadro 1.

Quadro 1 - Descrição dos brinquedos, segundo os materiais e as propostas. Brasília, 2017.

\begin{tabular}{|c|c|c|}
\hline Brinquedo & Materiais utilizados & Propostas para utilização \\
\hline Alinhavo & $\begin{array}{l}\text { Tampa plástica de embalagem } \\
\text { de leite ou sorvete e cordão ou cadarço }\end{array}$ & $\begin{array}{l}\text { Estimula várias áreas do } \\
\text { desenvolvimento, como } \\
\text { concentração, coordenação motora, } \\
\text { raciocínio lógico e espacial, além de } \\
\text { percepções visuais e táteis. }\end{array}$ \\
\hline Bilboquê & Garrafa PET, barbante e tampa de garrafa & $\begin{array}{l}\text { Além de trabalhar com a } \\
\text { coordenação motora, na tentativa de } \\
\text { que o pêndulo seja colocado na } \\
\text { "concha", também permite estimular } \\
\text { a noção de lateralidade e espaço. }\end{array}$ \\
\hline Binóculo & Miolo do papel higiênico e cola & $\begin{array}{l}\text { Contribui com a percepção no } \\
\text { observar e descrever o que está ao } \\
\text { redor, incluindo a orientação e a } \\
\text { mobilidade. }\end{array}$ \\
\hline Catapulta & Palito de picolé e elástico de borracha & $\begin{array}{l}\text { Incentiva a coordenação motora e } \\
\text { aborda conceitos físicos, como força } \\
\text { e direção. }\end{array}$ \\
\hline Chocalho & Embalagem de xampu, sementes ou bolinhas & $\begin{array}{l}\text { Aguça a audição de crianças menores, } \\
\text { além da coordenação motora. }\end{array}$ \\
\hline Jogo da Velha & Papelão e tampas plásticas de garrafa & $\begin{array}{l}\text { Promove o raciocínio lógico e noções } \\
\text { sobre diferença e semelhança. }\end{array}$ \\
\hline Fantoche & Caixa de sapato ou tetrapak, papel e canetas & $\begin{array}{l}\text { Fomenta a imaginação, a comunicação } \\
\text { e o conhecimento de personagens de } \\
\text { histórias infantis. }\end{array}$ \\
\hline Passa-bolinha & Garrafa PET, bolinha de gude e fita adesiva & $\begin{array}{l}\text { Engloba princípios da contagem } \\
\text { matemática e permite relacionar a } \\
\text { quantidade de bolas que caem e } \\
\text { aquelas que ficam em cada lado da } \\
\text { garrafa. }\end{array}$ \\
\hline Pião & $\mathrm{CD}$, bola de gude ou ping-pong e cola quente & $\begin{array}{l}\text { Desperta a coordenação motora e } \\
\text { aborda conceitos físicos, como força, } \\
\text { velocidade e atrito. }\end{array}$ \\
\hline Vai-e-vem & Garrafa PET e cordão & $\begin{array}{l}\text { Envolve a coordenação motora e o } \\
\text { senso de direção. }\end{array}$ \\
\hline
\end{tabular}




\section{Resultados e Discussão}

Nas sociedades industriais, a automação determina a exclusão do trabalho de muitas pessoas e faz com que a adolescência e a juventude tendam a se prolongar (DE MASI, 1999). Das poucas soluções vislumbradas pelo autor para a questão, estão: retardar o ingresso dos jovens no mercado de trabalho, mantendo-os na escola; e incrementar a formação e o adestramento profissional durante a vida produtiva.

No Brasil, face às crescentes desigualdades sociais, tem-se a urgência na busca de iniciativas institucionais que contribuam para atenuar seus efeitos. As oficinas de qualificação são importantes instrumentos para reduzir tais desigualdades, uma vez que ampliam a capacidade de inserção ou reinserção do indivíduo no mundo do trabalho, a partir de uma formação profissional inicial ou continuada. Sobre a inclusão social e sua promoção por meio da educação, Arroyo (2010) conclui que todos os indivíduos são sujeitos de direito à educação e à cultura, como forma de aprimoramento intelectual, por se tratar de bem derivado do direito à vida.

Há que se considerar também que o brincar na fase adulta estimula a criatividade (habilidade social relevante no mundo do trabalho), especialmente em tempos em que a tecnologia tem ocupado mais espaço na vida das pessoas. Moyles (2002) considera que a exploração de novos materiais, lugares e situações são atividades de relaxamento para os adultos que brincam. Para De Masi (1999), em cada tipo de sociedade os modos de gozo do tempo livre acabam se modelando aos modos de organização do tempo de trabalho. No entanto, o autor apresenta o homo ludens como uma nova ordem existencial em relação ao homo faber. Nesse contexto, considera a bricolagem como um dos ingredientes do tempo livre individual.

\section{Conclusões}

Quando consideramos a atuação das instituições parceiras na divulgação do projeto É brincando que se aprende, junto aos grupos atendidos, o interesse e participação destes nas oficinas, fica evidente a necessidade do estímulo à formação profissional inicial e continuada, especialmente quando se trata de grupos socialmente vulneráveis. O interesse na oferta das oficinas superou as expectativas da equipe executora. O público atendido com a realização das oficinas atingiu o quantitativo de 50 participantes, número superior ao esperado que era de 40, quando foi estimado 20 em cada uma das oficinas.

As crianças e os adultos que manipulam materiais de descarte, ampliam suas visões de mundo e tendem a considerar, em suas vidas, aspectos relacionados à consciência e à responsabilidade socioambiental, além da cidadania e do protagonismo social, que são importantes para a vida laboral. Pereira \& Hannas (2000) definem visão de mundo como um conjunto de crenças, ideias e valores, religiosos, filosóficos e científicos, através do qual cada grupo entende a realidade.

Quando consideramos o perfil social dos grupos atendidos no projeto É brincando que se aprende, a construção de brinquedos pedagógicos, além de possibilitar o ingresso ou reingresso no mundo do trabalho (tanto para a produção e comercialização de brinquedos acabados, quanto para a prestação de serviços de entretenimento em festas infantis), possibilitou o fortalecimento dos laços familiares e momentos de relaxamento e ludicidade (individual ou em grupo) que ganham relevância em grupos de pessoas privadas do acesso ao lazer tanto no aspecto social, quanto econômico e geográfico.

Por fim, chamamos a atenção ainda para a importância da extensão universitária na formação profissional do discente extensionista na perspectiva da indissociabilidade entre ensino, pesquisa e extensão e, dessa indissociabilidade na efetivação da educação de populações socialmente vulneráveis. A extensão universitária, além de proporcionar o desenvolvimento de habilidades sociais, tais como criatividade, colaboração e empatia, desperta nos estudantes a consciência e o compromisso social. Segundo Arroyo (2015), a educação de grupos socialmente vulneráveis não se efetivará enquanto os educadores não a efetivarem em sua formação.

\section{Fontes de Financiamento}

Instituto Federal de Educação, Ciência e Tecnologia de Brasília/IFB; Pró-reitoria de Extensão e Cultura/PREX; Edital Qualific Express nº 48/2016/RIFB. 


\section{Referências}

ARROYO, M. G. Os Movimentos Sociais e a construção de outros currículos. Educar em Revista, Curitiba, Brasil, n. 55, p. 47-68, jan./mar. 2015.

ARROYO, M. G. Políticas educacionais e desigualdades: à procura de novos significados. Educação $\mathcal{E}$ Sociedade, Campinas, v. 31, n. 113, p. 1075 - 1432, 2010.

BEE, H. A criança em desenvolvimento. 9a ed. Cidade: Artmed, 2003.

BRASIL. RCNEI. Referencial Curricular Nacional para a Educação Infantil, Brasília: MEC/SEF, v. 1, 1998. Disponível em: portal.mec.gov.br/seb/arquivos/pdf/rcnei_vol1.pdf Acesso em: 3 out. 2016

BRASIL. Lei da Primeira Infância. Lei $\mathrm{n}^{0}$ 13.257, de 8 de março de 2016. Disponível em: <http:// infanciaejuventude.tjrj.jus.br/informacoes/docs/lei-primeira-infancia.pdf> Acesso em: 23 mar. 2019.

CARDOSO, E. L. A importância do Brincar e do Jogo para o desenvolvimento da criança. Trabalho de Conclusão de Curso. Universidade Federal do Rio Grande do Sul. Porto Alegre, 2010.

DE MASI, D. O futuro do trabalho: fadiga e ócio na sociedade pós-industrial. $2^{a}$ ed., tradução Yadyr A. Figueiredo. Brasília: Editora UnB, 1999. 354 p.

MOYLES, J. R. Só brincar? O papel do brincar na educação infantil. Porto Alegre: Artmed, 2002. 199 p.

PEREIRA, I. L. L. \& HANNAS, M. L. Educação com consciência: fundamentos para uma nova abordagem pedagógica. Gente, São Paulo, 199 p. 2000.

SANTOS, I. A Importância do Brincar Para o Desenvolvimento Infantil. Rede Psi, 14 mar. 2011. [online]. Disponível em: http://www.redepsi.com.br/2011/03/14/a-import-ncia-do-brincar-para-o-desenvolvimento-infantil/. Acesso em: 23 mar. 2019.

SANTOS, S. K. S. L.; FERNANDES CRUVINEL, E.; ROCHA, R. M. M. F.; SOUSA, T. F.; SILVA, D. A.; PEREIRA, K. D. L. É brincando que se aprende: relato de experiência com a confecção de brinquedos. In: Encontro de Aprendizagem Lúdica, Brasília, 2., 2016. Anais [...] Brasília: UnB, 2016, p. 288-292. Disponível em: http://repositorio.unb.br/handle/10482/23065. Acesso em: 23 mar. 2019 .

SOUSA, K. Q.; SANTOS, C. P.; GAMA, L. B. Importância do brincar para o desenvolvimento infantil. In: Fórum Permanente de Inovação Profissional, 9., 2016, Anais [...], Aracaju: 2016, p. 1-11. Disponível em: https://eventos.set.edu.br/index.php/enfope/article/view/2035. Acesso em: 23 mar. 2019.

Submetido em: 28/03/2019. Aceito em: 08/10/2019. 